Van Roy, J.; Leemput, N.; Geth, F.; Büscher, J.; Salenbien, R.; Driesen, J., "Electric Vehicle Charging in an Office Building Microgrid With Distributed Energy Resources," Sustainable Energy, IEEE Transactions on , vol.PP, no.99, pp.1,1

doi: 10.1109/TSTE.2014.2314754

URL: http://ieeexplore.ieee.org/xpl/articleDetails.jsp?arnumber=6810874

(C2014 IEEE. Personal use of this material is permitted. Permission from IEEE must be obtained for all other uses, in any current or future media, including reprinting/republishing this material for advertising or promotional purposes, creating new collective works, for resale or redistribution to servers or lists, or reuse of any copyrighted component of this work in other works. 


\title{
Electric Vehicle Charging in an Office Building Microgrid With Distributed Energy Resources
}

\author{
Juan Van Roy, Student Member, IEEE, Niels Leemput, Student Member, IEEE, Frederik Geth, Student \\ Member, IEEE, Jeroen Büscher, Member, IEEE, Robbe Salenbien, and Johan Driesen, Senior Member, IEEE
}

\begin{abstract}
This paper discusses the charging of plug-in hybrid electric vehicles (PHEVs) in an existing office building microgrid equipped with a photovoltaic (PV) system and a combined heat and power (CHP) unit. Different charging strategies and charging power ratings for workplace charging are examined for their grid impact and their impact on the self-consumption of the locally generated electricity. The grid impact can be significantly reduced by using strategies that require limited future knowledge of the EV mobility behavior and limited communication infrastructure. These strategies allow a high number of EVs to be charged at an office building, even with a limited number of charging spots, due to the large standstill times.
\end{abstract}

Index Terms-Coordinated charging, Distributed energy resources, Electric vehicles, Microgrid, Office building.

\section{INTRODUCTION}

$\mathbf{R}$ ESIDENTIAL and commercial buildings consume about $32 \%$ of the global energy use. They are responsible for about $30 \%$ of the total end-use energy-related $\mathrm{CO}_{2}$ emissions, if the indirect upstream emissions are considered [1].

In the 20/20/20 targets, European climate and energy goals are set, such as a $20 \%$ increase in the share of renewable energy resources (RES) in the energy consumption and a $20 \%$ energy efficiency improvement by 2020 . The European Commission states energy goals and benchmarks at the level of individual buildings. A recent European Directive (2010/31/EU) requires that by 2020 all new buildings need to be nearly zero energy buildings (nZEB), targeting a high penetration of RES and energy efficiency in the built environment [2].

The integration of local distributed energy resources (DER) and more efficient technologies will result in a further electrification in buildings. From the grid point of view, photovoltaic (PV) systems, electric vehicles (EVs) and combined heat and power systems (CHPs) have an increased grid impact. Furthermore, EVs and CHPs have a certain flexibility to shift their electricity consumption respectively production in time [3], [4] and can facilitate the integration of RES [5]. They also have the advantage to reduce the consumption of greenhouse gas emitting fuels and reduce local pollutant emissions [1], [6]. An integrated energy system interconnecting loads and DER

J. Van Roy is funded through a VITO doctoral scholarship. N. Leempu has a Ph.D. grant of the Institute for the Promotion of Innovation through Science and Technology in Flanders (IWT-Vlaanderen).

All authors are with EnergyVille, 3600 Genk, Belgium.

J. Van Roy, N. Leemput, F. Geth, J. Büscher and J. Driesen are with the University of Leuven (KU Leuven), Department of Electrical Engineering (ESAT), Division Electa, Kasteelpark Arenberg 10, PB 2445, 3001 Leuven, Belgium (e-mail: Juan.VanRoy@esat.kuleuven.be).

J. Van Roy and R. Salenbien are with the Flemish Institute for Technological Research (VITO), Unit Energy Technology, 2400 Mol, Belgium. can be considered as a microgrid [7]. Also several storage solutions are envisioned, such as local battery storage [8].

\section{A. Impact on the Electricity Consumption}

EV charging will increase the buildings' electricity consumption. Given the Flemish mobility behavior, the specific power consumption of existing EVs and a charge efficiency of $90 \%, 2,350-3,750 \mathrm{kWh}$ is consumed on average per year for a full EV [9]. If EVs are only charged at home, this nearly doubles the average household electricity consumption $(3,500 \mathrm{kWh}$ per year in Flanders [10]). Charging at work might complement home charging to decrease this impact and to synchronize EV charging and PV power production.

\section{B. Impact on the Electricity Grid}

PV systems, EVs and CHPs have an increasing impact on the distribution grid [11]. The injection of electricity by means of PV systems and CHPs and the electricity consumption of EVs may lead to peak loads, higher resistive losses, voltage deviations and phase unbalance in the grid [11]-[13]. An overview of several grid impact indicators and load matching indicators is available in the literature [14].

There are two major differences between PV systems, EVs and CHPs. The main objective of PV systems is to produce as much electric energy as possible, while the main objective of EVs and CHPs is to fulfill respectively the mobility and heating requirements. Second, charging EVs and the heat/electricity generation by means of CHPs offer some flexibility, whereas PV production is determined by the irradiation of the sun. However in many countries, e.g. PV systems have to be curtailed or disconnected when the voltage becomes too high, leading to a loss in production [15].

\section{Flexibility of EV Charging Coordination}

In Flanders, on average, passenger vehicles are parked for more than $90 \%$ of the time. The average availability at home, at work and at other locations of a Flemish fleet is shown in Fig. 1. A small number of people work in a night shift. Thus, during the evening and night, a limited number of vehicles is parked at work. During daytime this is up to about $25 \%$ of the fleet. Thus, the EV availability at work is highly correlated with the period of possible PV power production. Fig. 1 also shows the high correlation between the EV availability and the increase in the considered office building power consumption.

In general, EV charging flexibility is limited by the mobility objectives, the available charging power ratings, battery state 


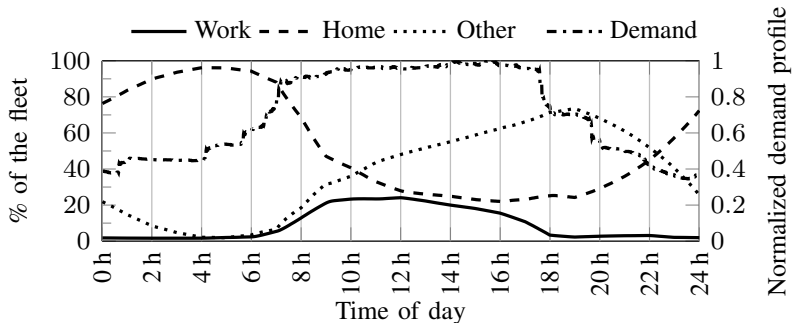

Fig. 1. Average availability of a Flemish vehicle fleet at home, at work and at other locations (including driving) [9] and the normalized average power consumption (dashdotted line) of the investigated building during weekdays.

of charge (SOC) and battery limitations. The flexibility, which allows to coordinate the EV charging [16], is limited by a charging path without any and with maximum charging delay. Vehicle-to-building and vehicle-to-grid service opportunities are envisioned [13]. Charging strategies such as individual peak shaving and droop-based voltage support [17] can be considered as support mechanisms for buildings and grids.

\section{Literature Overview on Coordinated Charging}

Several coordination scales of the EV integration have been investigated in the literature [16]: the vehicle, building, residential distribution and transmission grid scale. Besides, the integration with renewables has been studied [5], [16].

In [18], a small office building is considered. An economic analysis is performed to find the optimal building EV integration for vehicle-to-grid technology to minimize the cost. A dynamic optimal power flow method is proposed in [19] to minimize the operational cost. The electricity and heat generation by means of a CHP, and the EV charging are coordinated in an industrial microgrid including PV systems. In [20], the EV integration in commercial buildings with several DER is investigated. The EV charging is coordinated in order to minimize the daily energy costs. In [21], a larger building is studied for the integration of multiple PHEVs. Different coordination methods for PHEV charging (centralized and decentralized) are investigated for grid peak shaving.

In the literature, the focus of EV charging coordination in larger buildings lies on the charging schedule optimization for a certain objective which requires the future knowledge on the EV state and usage, building power consumption and/or electricity cost. Moreover, communication infrastructure may be required to coordinate the EV charging [22]. However, EV coordination strategies in larger buildings with limited prior knowledge and communication, or grid stabilizing strategies [17] are not extensively discussed.

\section{E. Scope of the Paper}

This paper focuses on simple, local EV charging strategies. No optimization to coordinate the EV charging is performed. The analyzed charging strategies require limited future knowledge on the mobility behavior: only the next departure time at work and the next commuter distance. They can be easily implemented on-board or in mode 3 charging infrastructure.
To charge EVs with a DER surplus, only local communication within the building is needed, e.g. with a building energy management system. The discussed strategies can still be complemented by a charging optimization strategy.

A real office building equipped with a large PV system and a CHP unit is discussed. Measurements for the electrical demand profiles and PV system and a simulation model for the CHP unit are available. The vehicles are modeled as PHEVs to meet all mobility requirements, even if the battery is depleted. A Flemish case study, is used to discuss the impact of the EV charging strategies in an office building. This allows to discuss the trends and what is already feasible with simple, implementable strategies (see Section V) before wide-spread coordination mechanisms are implemented. Storage solutions, such as battery storage, are not included in this paper.

Different charging strategies are assessed in terms of (i) their grid impact and (ii) the self-consumption of local generation. These charging strategies include uncoordinated charging, individual peak shaving at vehicle level (variable charging power) and anticipating on the DER power surplus. Different charging power ratings are evaluated. First, different EV penetration rates are examined. Since a company might only install a limited number of charging infrastructures, a fixed number of charging spots is considered in the second case.

\section{Methodology}

The different scenarios are compared regarding their grid impact and the self-consumption of the local generation.

\section{A. Grid Impact}

The bidirectional power flow between the building and the distribution grid is assessed. The load profiles are represented by modified box plots. Furthermore, the one percent peak power (OPP) of both the injection and demand power peaks are given. The OPP is defined as the mean power of the one percent highest power peaks [14].

\section{B. Self-consumption}

Cover factors represent the mismatch between local demand and production [14]. The self-consumption $\gamma_{S}$ defines how much of the generation is instantaneously consumed locally $\left(\min \left\{P_{S}, P_{D}\right\}\right)$ between time steps $t_{1}$ and $t_{2}$ :

$$
\gamma_{S}=\left[\int_{t_{1}}^{t_{2}} \min \left\{P_{S}, P_{D}\right\} d t\right]\left[\int_{t_{1}}^{t_{2}} P_{S} d t\right]^{-1},
$$

with $P_{S}$ and $P_{D}$ the local electricity supply and demand.

\section{SCENARIO DESCRIPTION}

The considered office building, the Siemens microgrid in Huizingen (Belgium), has a large PV park installed at the building site, while heat and electricity are generated by means of a small CHP. The building is part of the Volt-Air project, one of the five living labs for EVs in Flanders, Belgium [23]. This living lab focuses on the EV adoption in business fleets and their integration in company building microgrids. 
Measurement data ${ }^{1}$ is available: the buildings, the PV system, the CHP, the EV reservation tool and driving and charging logging. Only the power demand profile of the considered building and the power production profile of the PV system are used. Missing measurement points (about $7 \%$ ) are replaced by measurements from similar weeks with a comparable consumption or production profile. The CHP measurements show different operating regimes in the considered period. Therefore, these measurements are not used. Measurements are on a 5 min time resolution. The measurements are transformed to a 1 min time resolution. ${ }^{2}$ The proposed EV charging strategies will also work on higher time resolutions, since EVs have to react within $5 \mathrm{~s}$ [24]. The simulations in this paper cover the first five months of 2013 (January - May).

\section{A. Distributed Energy Resources}

1) Photovoltaic System: A large PV installation $\left(500 \mathrm{~kW}_{\mathrm{p}}\right)$, covering an area of about $10000 \mathrm{~m}^{2}$, delivers the energy for the building and the EVs. The surplus is injected into the grid. During the first five months $164.5 \mathrm{MWh}$ is produced.

2) CHP Unit: The CHP delivers only hot water to the cafeteria. For the CHP electricity production profile $(9 \mathrm{~kW}$ electric power), the COGENscan 2008 simulation tool is used [25]. This tool allows to calculate a CHP production profile with a $1 \mathrm{~h}$ time resolution. However, it is based on a heat and hot water demand profile for a reference office building. Therefore, it is assumed here that the CHP is heat driven and delivers both heat and hot water, without thermal storage. The CHP is dimensioned for the heat base load and therefore no partial load operation is considered. During the considered period, 18.7 MWh of electricity is produced.

3) Complementarity PV and CHP: Fig. 2 shows the seasonal complementary between PV and CHP systems. This figure shows the monthly energy production of both systems scaled to their respective month with maximum production. Since the CHP is heat driven, it is expected that the energy production in winter will be higher than in spring, while the PV system produces more electricity in spring/summer.

In this case study, the electrical power of the CHP is limited compared to the PV system $\left(9 \mathrm{~kW}_{\mathrm{p}}\right.$ vs. $\left.500 \mathrm{~kW}_{\mathrm{p}}\right)$. In future work, an optimal sizing of both systems and an optimal CHP coordination strategy may lead to a more optimal complementary of electricity production.

${ }^{1}$ Accuracy of $1 \%$ for the current transformer and respectively $0.5 \%$ and $0.2 \%$ for the PV and building power measurement devices at nominal current.

${ }^{2}$ Constant power profile on a $1 \mathrm{~min}$ time resolution within the time resolution of the original data: building $(5 \mathrm{~min}), \mathrm{PV}(5 \mathrm{~min})$ and CHP $(1 \mathrm{~h})$

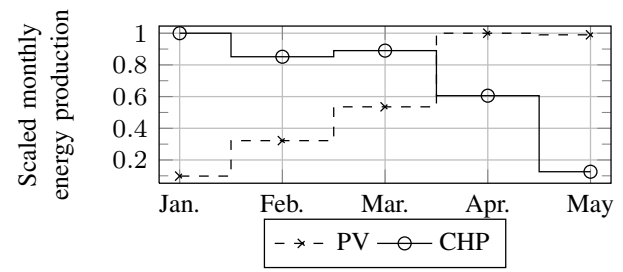

Fig. 2. Scaled monthly energy production of the PV system and CHP to their respective month with maximum production.

\section{B. Electric Vehicles}

The EV model consists of three models: a battery model, the mobility behavior and the charging strategies. Limited future knowledge (the next departure time at work and commuter distance) is required for the charging strategies.

1) Battery Model: The battery model is implemented with dynamic SOC equations and battery parameter constraints [26]. The SOC is calculated for each time step $t$ by:

$$
S O C_{t}=S O C_{t-1}-\delta_{t}^{\mathrm{sd}}+\left(\eta_{c} P_{t}^{c} T_{s}-\eta_{d}^{-1} P_{t}^{d} T_{s}\right) / E_{\mathrm{nom}},
$$

with $\delta_{t}^{\text {sd }}$ the self-discharge [\%] of the battery during a time step $t$, and $T_{s}[\mathrm{~s}]$ the time step resolution. The efficiency during charging $\eta_{c}$ and discharging $\eta_{d}$ of the power electronics and battery (Li-ion) are respectively $88.2 \%$ and $98.0 \%$ [26]. $P_{t}^{c}$ and $P_{t}^{d}$ are respectively the charge and discharge power [W] at time step $t$, with $P_{t}^{c} P_{t}^{d}=0$.

The EVs are modeled as PHEVs such that all mobility requirements are met, even if the battery is depleted. The nominal battery capacities $E_{\text {nom }}$ are 10,15 and $20 \mathrm{kWh}$ for respectively the subcompact, midsize and large vehicles. The usable battery capacity $E_{\text {eff }}$ is limited to $80 \%$ of $E_{\text {nom }}$ to extend the battery cycle life [27].

2) Mobility Behavior: A mobility simulation tool is used to generate the mobility behavior profiles for a fleet of 100 EVs [9]. Flemish statistical data on transport behavior is used to generate realistic driving patterns for each individual vehicle in the fleet (work and nonwork related trips): whether the vehicle is driving or standing still and where it is parked (e.g. at home, work, a visit) [28]. By using this statistical data, it is assumed that the mobility behavior with EVs remains the same as with conventional vehicles.

Between 36.2 and $46.9 \%$ of all vehicles in the fleet are used for work trips besides other trips [9]. Here, all EVs selected for the fleet are used for work related trips next to the other trips. Only business trips may overlap during the trip to and the presence at work. Each vehicle has a fixed commuter distance. Also the work shift, departure and return hours are fixed since $82 \%$ of the population has fixed working hours [28]. The time of departure and return (on a 1 min resolution) is variable with a uniform probability function in the fixed departure and return hours. Weekend shifts are considered. Thus, a number of vehicles parked at work during the weekend.

The vehicles are divided in subcompact, midsize and large vehicles to take into account the variation of vehicle types and fuels (gasoline and diesel) on the yearly driven distance. These vehicle categories each have their specific power consumption [9], respectively $0.185,0.220$ and $0.293 \mathrm{kWh} / \mathrm{km}$ in this paper. These numbers include a correction factor of $15 \%$ to take the impact of the ambient temperature, wind, altitude, road grade and surface into account [29].

3) Charging Strategies at Home: Home charging is not the scope of this paper. However, the amount of charging at home will influence the charging at work. Two home charging strategies are considered, one for which the maximum amount of energy is charged at home (H.1) and another for which a sufficient amount of energy is charged in order to arrive at work with a depleted battery (H.2). Depending on the 
commuter distance, EVs may not be fully charged at home. For both strategies, the EVs start charging when arriving at home at maximum power $\left(P_{\max }\right)$.

This second strategy considers the benefits from the combination of the short commuter distance, the long standstill times at work and the decreased home charging impact. According to the Flemish mobility statistics, the average commuter distance (all transport means) is $18.8 \mathrm{~km} \mathrm{[28].} \mathrm{For} \mathrm{about} 90 \%$ of the people who commute by car, it is less than $50 \mathrm{~km}$.

4) Charging Strategies at Work: EV charging at home is complemented by charging at work. The following charging strategies at work are investigated:

- Uncoordinated charging (W.1): Charging starts after arrival at work at maximum charging power $P_{\max }$.

- Individual peak shaving (W.2): Charging starts after arrival at work at a reduced charging power $P_{\text {red }}$.

- W.2 and DER surplus (W.3): Charging starts after arrival at work at $P_{\text {red }}$. The surplus of locally produced electricity is divided over all grid-connected EVs in order not to give preference to one or more vehicles.

The combinations of charging strategies are depicted in Table I. $P_{\text {red }}$ is calculated with the knowledge of the next departure time $t_{d}$ at work and the required energy $E_{\text {req }}$ to fully charge the battery by the next departure moment at work:

$$
P_{\text {red }}=\min \left(E_{\text {req }} / \Delta t, P_{\max }\right),
$$

with $\Delta t$ the time remaining until $t_{d}$. To prevent a low partial load efficiency of the power electronics, it is assumed that the minimum charging power is $10 \%$ of the charging power rating, e.g. $330 \mathrm{~W}$ for a power rating of $3.3 \mathrm{~kW}$.

Strategy W.3 requires a detection of the number of gridconnected EVs by the building energy management system, through interfacing with the EV supply equipment (EVSE). The energy management system communicates the extra power that can be drawn by the EVs by changing the PWM duty cycle of the control pilot as defined in IEC 309-2 [30]. It is assumed that the building power demand and DER power production are measured and communicated with the building energy management system.

TABLE I

EV CHARGING STRATEGIES FOR HOME AND WORK CHARGING.

\begin{tabular}{lccccc}
\hline Charging & \multicolumn{3}{c}{ Work } & \multicolumn{3}{c}{ Home } \\
\cline { 2 - 6 } Strategy & W.1 & W.2 & W.3 & H.1 & H.2 \\
\hline $1 \mathrm{a}$ & $\mathrm{x}$ & & & $\mathrm{x}$ & \\
$2 \mathrm{a}$ & & $\mathrm{x}$ & & $\mathrm{x}$ & \\
$3 \mathrm{a}$ & & & $\mathrm{x}$ & $\mathrm{x}$ & \\
\hline $1 \mathrm{~b}-3 \mathrm{~b}$ & (Work: see $1 \mathrm{a}-3 \mathrm{a})$ & & $\mathrm{x}$ \\
\hline
\end{tabular}

5) Charging Power Ratings: Different charging power ratings are examined as depicted in Table II, which are typical for mode 2 and mode 3 charging as defined in IEC 61851-1 [31]. At home, a charging power rating of $3.3 \mathrm{~kW}$ is taken for a single-phase $230 \mathrm{~V} / 16$ A connection, including a $10 \%$ margin to take into account the maximum allowed voltage deviations (EN50160). Also at work, the charging power rating of $3.3 \mathrm{~kW}$
TABLE II

EV CHARGING POWER RATINGS FOR HOME AND WORK CHARGING.

\begin{tabular}{llcr}
\hline Place & Connection & $\begin{array}{c}\text { Maximum } \\
\text { current }\end{array}$ & $\begin{array}{r}\text { Power } \\
\text { rating }\end{array}$ \\
\hline Home & Single-phase & $16 \mathrm{~A}$ & $3.3 \mathrm{~kW}$ \\
\hline \multirow{2}{*}{ Work } & Single-phase & $16 \mathrm{~A}$ & $3.3 \mathrm{~kW}$ \\
& Single-phase & $32 \mathrm{~A}$ & $6.6 \mathrm{~kW}$ \\
& Three-phase & $32 \mathrm{~A}$ & $19.8 \mathrm{~kW}$ \\
\hline
\end{tabular}

is assessed. Furthermore, two higher charging powers are investigated for mode 3 dedicated charging infrastructure which allow currents up to 32 A for respectively single $(6.6 \mathrm{~kW})$ and three-phase $(19.8 \mathrm{~kW})$ connections [32].

6) EVSE: In Section IV, two different cases will be discussed with each an assumption regarding the availability of the required EVSE. In the first case (Section IV-C), the impact of a fixed number of EVs is investigated, for which it is assumed there are enough charging spots available at any time for all EVs to be charged.

In the second case (Section IV-D), a fixed number of charging spots $X$ at work is assumed. The EVs are charged (at maximum power) in order of arrival and depending on the charging spot availability. It is assumed that each vehicle can be plugged in at arrival. This means there are for instance a number $X$ of dedicated charging infrastructures, which can control the different sockets by e.g. the use of relays, in order that a maximum of $X$ sockets are delivering power.

\section{RESULTS}

This section first describes the results of the reference scenarios without EVs. Thereafter, the results of the different charging strategies for different charging power ratings, EV penetration rates and number of charging spots are discussed for the considered period (January - May 2013).

\section{A. Reference Scenario: No EVs}

Fig. 3 shows the load duration diagram of the aggregated building load profile, PV and CHP production profile without EVs. The demand and injection peak power are respectively $251 \mathrm{~kW}$ and $412.6 \mathrm{~kW}$, while the demand and injection OPP are $179.6 \mathrm{~kW}$ and $371.2 \mathrm{~kW}$. There is a high simultaneity of the building load profile and the PV and CHP production

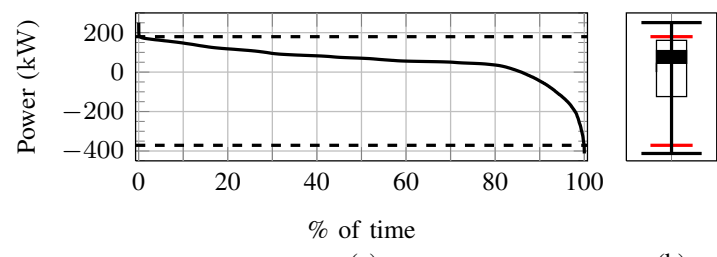

(a)

(b)

Fig. 3. Reference scenario results: (a) Load duration diagram and the OPPs (dashed line) and (b) the modified box plot to represent the load duration diagram. The inner box (black) spans the 25 th to 75 th power percentiles. The outer box (white) spans the 5 th to 95 th percentiles. The outer whiskers extend to the minimum and maximum values. The OPPs (shorter line) are included. 
during weekdays. As a result, the self-consumption of PV and CHP power is $70 \%$. However, the low electricity consumption during the weekend results in high grid injection peaks.

\section{B. EV Energy Consumption at Work}

Table III shows the average EV energy consumption at the office building. When the charging power rating increases, the relative energy consumption increase decreases for higher charging powers. Thus, higher charging powers have a smaller impact as a result of the long standstill times at work.

When EVs are fully charged at home, the energy consumption at work amounts to about $21.5 \%$ of the total charge energy at home and work combined. If EVs are only partly charged at home, the average charge energy at work is more than doubled. This is advantageous regarding the grid impact at home, and the possible higher self-consumption at work.

TABLE III

AVERAGE CHARGING ENERGY AT THE OFFICE BUILDING FOR THE DIFFERENT CHARGING POWER RATINGS.

\begin{tabular}{lccc}
\hline Charging power rating & $\mathbf{3 . 3} \mathrm{kW}$ & $\mathbf{6 . 6} \mathrm{kW}$ & $\mathbf{1 9 . 8} \mathrm{kW}$ \\
\hline Fully charged at home & $296.5 \mathrm{kWh}$ & $308.1 \mathrm{kWh}$ & $317.9 \mathrm{kWh}$ \\
Partly charged at home & $725.9 \mathrm{kWh}$ & $751.3 \mathrm{kWh}$ & $767.1 \mathrm{kWh}$ \\
\hline
\end{tabular}

\section{Fixed Number of EVs}

First, the different charging strategies are assessed for different EV fleet sizes in terms of the grid impact and the self-consumption of locally generated electricity.

1) Charging Simultaneity: Table IV shows the maximum number of EVs charging simultaneously during the whole period and the averaged maximum for weekdays. For charging without coordination, the maximum number of EVs charging simultaneous is 25 and 51 when EVs are respectively fully and partly charged at home. Partly charging at home increases the charging duration at work. As a result the charging simultaneity increases. This is also the result when individual peak shaving is applied at work. On the other hand, charging simultaneity decreases for an increasing charging power. The

TABLE IV

CHARGING SIMULTANEITY [NUMBER OF EVS], BOTH THE MAXIMUM FOR THE WHOLE PERIOD AND THE AVERAGED MAXIMUM FOR WEEKDAYS, FOR THE DIFFERENT SCENARIOS (CS) AND A FLEET OF 100 EVS FOR THE DIFFERENT CHARGING POWER RATINGS (P).

\begin{tabular}{|c|c|c|c|c|c|}
\hline \multirow[t]{2}{*}{ CS } & \multirow{2}{*}{$\begin{array}{c}\mathbf{P} \\
(\mathrm{kW})\end{array}$} & \multicolumn{2}{|c|}{ Fully charge at home } & \multicolumn{2}{|c|}{ Partly charge at home } \\
\hline & & Maximum & Average & Maximum & Average \\
\hline \multirow{3}{*}{1} & 3.3 & 25 & 17.6 & 51 & 38.2 \\
\hline & 6.6 & 20 & 12.3 & 38 & 26.0 \\
\hline & 19.8 & 13 & 5.7 & 21 & 11.6 \\
\hline \multirow{3}{*}{2} & 3.3 & 51 & 41.3 & 70 & 54.1 \\
\hline & 6.6 & 46 & 35.8 & 70 & 52.2 \\
\hline & 19.8 & 31 & 21.9 & 57 & 44.2 \\
\hline \multirow{3}{*}{3} & 3.3 & 51 & 40.6 & 70 & 52.7 \\
\hline & 6.6 & 46 & 35.5 & 70 & 50.9 \\
\hline & 19.8 & 31 & 21.7 & 57 & 44.2 \\
\hline
\end{tabular}

impact of scenario 3 compared to scenario 2 is only limited as a result of the limited shorter charging time.

2) Grid Impact: Fig. 4 shows the modified box plots of the load diagrams for the different scenarios, EV penetration rates and charging power ratings. A straightforward observation is the increasing grid impact for an increasing charging power rating and number of EVs. The impact on the injection peak power and injection OPP is very limited. This is the result of the low building power consumption and the low number of EVs at work during the weekend. Nevertheless, for an increasing number of EVs, the self-consumption will rise which is shown by the percentiles which increase.

In the first scenario, the EVs are charged without coordination. The peak demand power increases between $0 \%$ to $42.5 \%$ for scenario 1a depending on the charging power rating and number of EVs. The increase of the OPP is between $1.5 \%$ to $58.4 \%$. When the EVs are not fully charged at home (scenario 1b), the peak demand powers and OPPs will increase compared to scenario 1a.

When individual peak shaving is applied (scenario 2), the EVs will charge at reduced power if possible. Due to the long standstill times at work and the low commuter distances, the average charging power is remarkably lower when charging. As a result, the peak demand powers and OPPs in scenario $2 \mathrm{a}$ are lower than in scenario 1a. The injection peak powers decrease up to $2.1 \%$ compared to the reference scenario.

In scenario 3, the individual peak shaving can be overruled to charge the DER surplus. As a result, the self-consumption will increase, shown by the increasing 5 th percentile and the

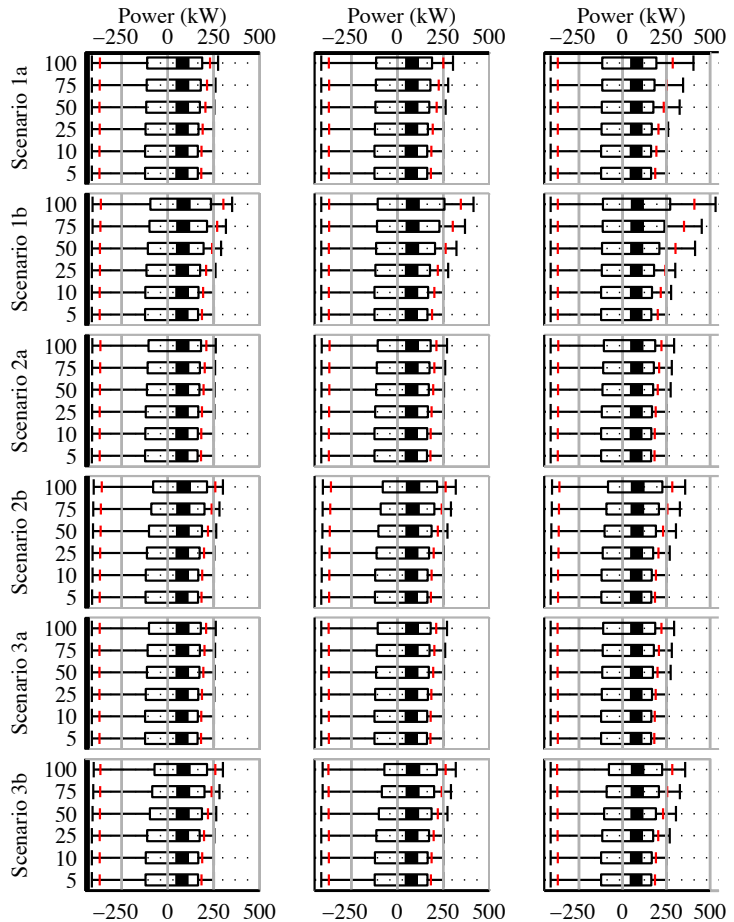

Fig. 4. Load duration diagrams (modified box plots) for the different charging scenarios and $\mathrm{EV}$ penetration rates (y-axis) for a charging power rating of $3.3 \mathrm{~kW}$ (left), $6.6 \mathrm{~kW}$ (middle) and $19.8 \mathrm{~kW}$ (right). 
decreasing demand OPP. However, the peak injection powers are identical to the reference scenario and are therefore higher compared to the second scenario. Charging the surplus of local electricity results in a decreased charging time and thus lowering the simultaneity with any high production peaks at future time steps.

3) Self-consumption Impact: The self-consumption of the local PV and CHP electricity production without EVs is $70 \%$. Table V shows the self-consumption for the different scenarios and charging power ratings. In order to keep the table clear, only the results for 5, 50 and $100 \mathrm{EVs}$ are shown.

Because of the high simultaneity of the EV charging and the $\mathrm{PV}$ production, the integration of $\mathrm{EV}$ charging in the office building will increase the self-consumption. When the EVs are partly charged at home (charging strategy H.2), the self-consumption increases more due to the longer charging time. For a fixed EV penetration rate, the self-consumption decreases for higher charging power ratings. A faster charging time results in a lower simultaneity with DER production.

When the EVs are charged at a lower charging power (individual peak shaving), the self-consumption increases compared to the first scenario. Spreading the charging during the day at work increases the simultaneity between the EV charging and the local electricity production. Due to the long standstill times, the differences between the different charging power ratings is limited. However, charging at a higher power rating increases the minimal charging power. Therefore, the self-consumption might decrease because of a lower simultaneity with the local generation.

In the third scenario, individual peak shaving is applied, but it can be overruled to charge the surplus of local electricity production. Therefore, this results in the highest selfconsumptions, up to almost $7 \mathrm{pp}$ compared to scenario and up to about $10 \mathrm{pp}$ compared to the reference scenario. Although, the difference with scenario 2 is limited.

TABLE V

SELF-CONSUMPTION [\%] FOR THE DIFFERENT CHARGING SCENARIOS (CS) AND EV PENETRATION RATES (5, 50 AND 100 EVS) FOR THE DIFFERENT CHARGING POWER RATINGS (P).

\begin{tabular}{cccccccc}
\hline CS & $\mathbf{P}$ & \multicolumn{3}{c}{ Fully charge at home } & \multicolumn{3}{c}{ Partly charge at home } \\
& $(\mathrm{kW})$ & 5 & 50 & 100 & 5 & 50 & 100 \\
\hline \multirow{4}{*}{1} & 3.3 & 70.1 & 71.6 & 73.0 & 70.4 & 73.8 & 76.6 \\
& 6.6 & 70.0 & 71.3 & 72.4 & 70.2 & 72.6 & 74.5 \\
& 19.8 & 70.0 & 71.1 & 71.9 & 70.1 & 71.7 & 73.1 \\
\hline \multirow{3}{*}{2} & 3.3 & 70.2 & 72.2 & 74.1 & 70.5 & 74.8 & 78.9 \\
& 6.6 & 70.2 & 72.2 & 74.1 & 70.5 & 74.9 & 79.0 \\
& 19.8 & 70.2 & 72.0 & 73.7 & 70.5 & 74.6 & 78.3 \\
\hline \multirow{3}{*}{3} & 3.3 & 70.2 & 72.8 & 75.1 & 70.6 & 75.8 & 80.2 \\
& 6.6 & 70.2 & 72.9 & 75.1 & 70.7 & 76.2 & 80.5 \\
& 19.8 & 70.2 & 72.5 & 74.4 & 70.6 & 75.5 & 79.4 \\
\hline
\end{tabular}

\section{Fixed Number of Charging Spots}

A fixed number of charging spots is assumed here for a fleet of $100 \mathrm{EVs}$. It is assumed that all EVs can be plugged in at arrival and will be charged in order of arrival (Section III-B6).
1) Amount of EVs Charged: The average number of EVs used for work trips on weekdays is 65.7. Table VI (A) shows the average amount of these EVs that will be charged at least for one minute a day. Not all EVs will be fully charged due to the limited number of charging spots (Table VI (B)).

A limited number of charging spots allow to fully charge a high number of EVs. A higher power charging rating increases the number of EVs being fully charged. However, this impact is less for a higher number of charging spots. Therefore, the cost difference for the infrastructure should be assessed regarding the needs to fully charge all vehicles at work. Charging an EV partly at home limits the number of EVs that can be (fully) charged at work. To attain similar results as when EVs are fully charged at home, more charging spots and a higher charging power rating are required.

TABLE VI

(A) AVERAGE AMOUNT OF EVS CHARGED [\%] AND (B) FRACTION OF FULLY CHARGED EVS OF (A) [\%] AT WORK FOR A NUMBER OF CHARGING SPOTS (1, 6 AND 10) FOR THE DIFFERENT CHARGING POWER RATINGS (P).

\begin{tabular}{cccccccc}
\hline & P & \multicolumn{3}{c}{ Fully charge at home } & \multicolumn{3}{c}{ Partly charge at home } \\
& $(\mathrm{kW})$ & 1 & 6 & 10 & 1 & 6 & 10 \\
\hline & 3.3 & 34.0 & 87.7 & 93.8 & 13.8 & 58.2 & 77.9 \\
(A) & 6.6 & 51.4 & 94.2 & 95.3 & 19.9 & 77.9 & 90.6 \\
& 19.8 & 82.7 & 95.4 & 95.4 & 43.9 & 94.5 & 95.3 \\
\hline & 3.3 & 84.2 & 85.5 & 92.7 & 50.7 & 50.2 & 51.5 \\
(B) & 6.6 & 86.2 & 96.3 & 96.3 & 69.1 & 72.1 & 89.3 \\
& 19.8 & 95.6 & 98.8 & 98.8 & 83.9 & 97.6 & 98.0 \\
\hline
\end{tabular}

2) Grid Impact: Fig. 5 shows the load profiles for fully and partly charging at home. Since the number of charging spots is lower than the number of EVs to be charged, the charging of the different EVs is spread in time. Similar conclusions can be taken for the grid impact as in scenario 2 in Section IV-C.

3) Self-consumption Impact: Table VII shows the impact on the self-consumptions for the different scenarios and charging power ratings for 1, 6 and 10 charging spots. An increase in self-consumption of up to $7.5 \mathrm{pp}$ compared to the reference scenario is possible. Similar, the self-consumption increases when the EVs are partly charged at home, due to the charging duration increase at work. However, increasing the charging power does not always lead to a higher self-consumption since

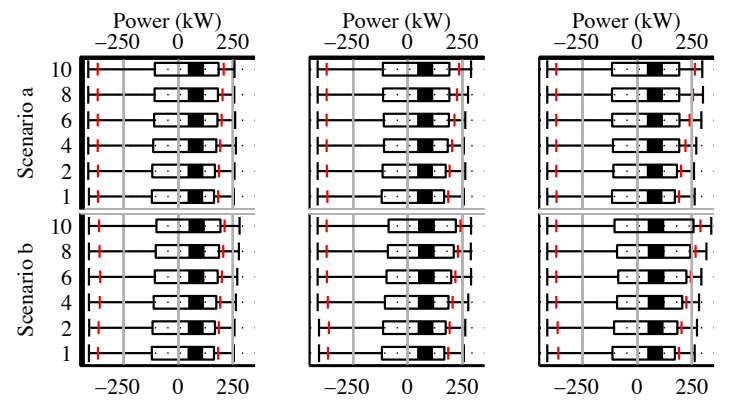

Fig. 5. Load duration diagrams (modified box plots) for (a) fully and (b) partly home charging for different number of charging spots (y-axis) for a charging power rating of $3.3 \mathrm{~kW}$ (left), $6.6 \mathrm{~kW}$ (middle) and $19.8 \mathrm{~kW}$ (right). 
TABLE VII

SELF-CONSUMPTION [\%] FOR THE DIFFERENT SCENARIOS (CS) AND NUMBER OF CHARGING SPOTS (1, 6 AND 10) FOR THE DIFFERENT CHARGING POWER RATINGS $(\mathrm{P})$

\begin{tabular}{ccccccc}
\hline $\mathbf{P}$ & \multicolumn{3}{c}{ Fully charge at home } & \multicolumn{3}{c}{ Partly charge at home } \\
$(\mathrm{kW})$ & 1 & 6 & 10 & 1 & 6 & 10 \\
\hline 3.3 & 70.8 & 73.0 & 73.4 & 70.9 & 74.1 & 75.6 \\
6.6 & 71.4 & 73.2 & 72.6 & 71.8 & 76.0 & 77.5 \\
19.8 & 72.9 & 71.9 & 71.9 & 74.0 & 74.5 & 73.2 \\
\hline
\end{tabular}

the charging time will become shorter resulting in a lower simultaneity with any local generation afterwards.

In Section IV-C, the self-consumption increased with an increasing number of EVs. However, for a fixed number of EVs and charging power rating, there is an optimal number of charging spots to maximize the self-consumption. Note that it is assumed that the EVSE can switch charging between EVs, thus it is not required for EV drivers to move their EV after a full charge or before starting the charging process. Increasing the number of charging spots will lead to a higher self-consumption since more EVs are charged. For a certain number of charging spots all EVs are charged and further increasing this number will decrease the self-consumption since the simultaneity with the DER production will decrease.

\section{CONCLUSIONS}

The charging of EVs in an existing office building, equipped with a PV system and a CHP unit, is discussed. Complementing the home with work charging increases the electric range, but decreases the electricity consumption and grid impact at home, which can benefit both the EV owner and grid operator. If EVs are fully charged at home, $20 \%$ of the total energy charged is charged at work. If they are partly charged at home, this is nearly $50 \%$. Although, to overcome range-anxiety, people might be tended to foresee an extra margin at home.

The grid impact can be significantly reduced by using local charging strategies that rely on limited future knowledge of the EV mobility behavior and limited or no communication infrastructure within the building. These strategies allow a high number of EVs to be charged at an office building with a lower grid impact and an increased DER self-consumption.

Individual peak shaving reduces the average charging power significantly. It can be implemented on the EV on-board battery management system or in a mode $3 \mathrm{EVSE}$ and requires no communication within the building. However, the knowledge of the next departure time at work is required. An incentive for the EV driver is needed when it is done on-board. For a mode 3 EVSE, the typical working hours can be estimated, or EV drivers need an incentive to specify the time of departure.

The trend towards higher charging power ratings can be combined with individual peak shaving. It may allow to meet range anxiety if the driving behavior requires a higher charging power. However, it is important to assess the extra infrastructure costs for its benefits and drawbacks [33]. Despite the charging simultaneity for higher charging powers is lower, the grid impact is higher and the self-consumption might decrease.
Therefore, the increased effectiveness of higher charging powers decreases for charging places with long standstill times.

Due to the low power consumption and low EV availability at work in the weekend, the impact on the grid injection peak is limited, requiring other solutions. Moreover, overruling the individual peak shaving to charge the DER surplus has a limited impact on the self-consumption, thus the cost-benefits of this implementation have to be considered.

Local storage can be considered for microgrids and will influence the results. The self-consumption will increase. Thus, the injected and consumed energy in and from the grid decreases. However, the impact of local storage depends on the charging and discharging strategy and the storage sizing.

For a limited number of $X$ EVSE, a high number of EVs can be fully charged if they are charged at maximum power in order of arrival at work. It is assumed that all EVs can plug in at arrival and the EVSEs can control the different sockets such that a maximum of $X$ sockets can deliver power simultaneously. A limited number of charging spots spreads the EV charging. This limits the grid impact and increases the DER simultaneity.

\section{REFERENCES}

[1] International Energy Agency, Energy technology perspectives 2012: Pathways to a clean energy system, Paris, France, 2012.

[2] The European Parliament, "Directive 2010/31/EU of the European Parliament and the Council on 19 May 2010 on the energy performance of buildings (recast)," 2010.

[3] G. Heydt, "The impact of electric vehicle deployment on load management strategies," IEEE Power Eng. Rev., vol. 3, no. 5, pp. 41-42, May 1983.

[4] T. Nuytten, B. Claessens, K. Paredis, J. Van Bael, and D. Six, "Flexibility of a combined heat and power system with thermal energy storage for district heating," Appl. Energy, vol. 104, pp. 583-591, Apr. 2013.

[5] B. Mathiesen and H. Lund, "Comparative analyses of seven technologies to facilitate the integration of fluctuating renewable energy sources," IET Renew. Power Gen., vol. 3, no. 2, pp. 190-204, Jun. 2009.

[6] M. Duvall, E. Knipping, M. Alexander, L. Tonachel, and C. Clarc, "Environmental assessment of plug-in hybrid electric vehicles," Electric Power Research Institute, Tech. Rep. 1015325, 2007.

[7] M. Smith and D. Ton, "Key connections: The U.S. Department of Energy's Microgrid Initiative," IEEE Power Energy Mag., vol. 11, no. 4, pp. 22-27, 2013.

[8] J. Leadbetter and L. Swan, "Battery storage system for residential electricity peak demand shaving," Energy and Buildings, vol. 55, pp. 685-692, Dec. 2012

[9] J. Van Roy, N. Leemput, S. De Breucker, F. Geth, P. Tant, and J. Driesen, "An availability analysis and energy consumption model for a Flemish fleet of electric vehicles," in European Electric Vehicle Congr., Brussels, Belgium, Oct. 2011, pp. 1-12.

[10] (2013, Jun.) Flemish Regulator for the Energy and Gas markets (VREG). [Online]. Available: http://www.vreg.be

[11] R. Passey, T. Spooner, I. MacGill, M. Watt, and K. Syngellakis, "The potential impacts of grid-connected distributed generation and how to address them: A review of technical and non-technical factors," Energy Policy, vol. 39, no. 10, pp. 6280-6290, Oct. 2011.

[12] R. Baetens, R. De Coninck, J. Van Roy, B. Verbruggen, J. Driesen, L. Helsen, and D. Saelens, "Assessing electrical bottlenecks at feeder level for residential net zero-energy buildings by integrated system simulation," Appl. Energy, vol. 96, pp. 74-83, Aug. 2012.

[13] K. Clement, E. Haesen, and J. Driesen, "The impact of vehicle-to-grid on the distribution grid," Electric Power Syst. Research J., vol. 81, no. 1, pp. 185-192, Jan. 2011.

[14] B. Verbruggen, R. De Coninck, R. Baetens, D. Saelens, L. Helsen, and J. Driesen, "Grid impact indicators for active building simulation," in IEEE PES Innovative Smart Grid Technologies (ISGT), Anaheim, CA, Jan. 2011, pp. 1-6.

[15] Automatic disconnection device between a generator and the public lowvoltage grid, DIN VDE Std. 0126-1-1, Feb. 2006. 
This is the author's version of an article that has been published in this journal. Changes were made to this version by the publisher prior to publication. The final version of record is available at http://dx.doi.org/10.1109/TSTE.2014.2314754

[16] N. Leemput, J. Van Roy, F. Geth, P. Tant, and J. Driesen, "Comparative analysis of coordination strategies for electric vehicles," in IEEE PES Innovative Smart Grid Technologies (ISGT) Europe, Manchester, United Kingdom, Dec. 2011, pp. 1-8.

[17] F. Geth, N. Leemput, J. Van Roy, J. Büscher, R. Ponnette, and J. Driesen, "Voltage droop charging of electric vehicles in a residential distribution feeder," in IEEE PES Innovative Smart Grid Technologies (ISGT) Europe, Berlin, Germany, Oct. 2012, pp. 1-8.

[18] I. Momber, T. Gómez, G. Venkataramanan, M. Stadler, S. Beer, J. Lai, C. Marnay, and V. Battaglia, "Plug-in electric vehicle interactions with a small office building: An economic analysis using DER-CAM," in IEEE PES General Meeting, Minneapolis, MN, Jul. 2010, pp. 1-8.

[19] S. Derakhshandeh, A. Masoum, S. Deilami, M. Masoum, and M. Hamedani Golshan, "Coordination of generation scheduling with PEVs charging in industrial microgrids," IEEE Trans. Power Syst., vol. 28, no. 3, pp. 3451-3461, Aug. 2013.

[20] M. Bozchalui and R. Sharma, "Analysis of electric vehicles as mobile energy storage in commercial buildings: Economic and environmental impacts," in IEEE PES General Meeting, San Diego, CA, Jul. 2012, pp. $1-8$.

[21] H. K. Nguyen and J. B. Song, "Optimal charging and discharging for multiple PHEVs with demand side management in vehicle-to-building," J. of Commun. and Netw., vol. 14, no. 6, pp. 662-671, Dec. 2012.

[22] J. Huang, V. Gupta, and Y.-F. Huang, "Scheduling algorithms for PHEV charging in shared parking lots," in Amer. Control Conf., Montréal Canada, Jun. 2012, pp. 276-281.

[23] (2013, Jun.) Flemish Living Lab Electric Vehicles - Volt-Air Platform [Online]. Available: http://www.livinglab-ev.be

[24] A. Brooks, "Vehicle charging as a source of grid frequency regulation," in EVS27 Int. Battery, Hybrid and Fuel Cell Elect. Vehicle Symp., Barcelona, Spain, Nov. 2013, pp. 1-6.

[25] (2013, Jun.) COGEN Vlaanderen - Rekentools voor prehaalbaarheid. [Online]. Available: http://www.cogenvlaanderen.be

[26] J. Tant, F. Geth, D. Six, and J. Driesen, "Multiobjective battery storage to improve PV integration in residential distribution grids," IEEE Trans. Sustain. Energy, vol. 4, no. 1, pp. 182-191, Jan. 2013.

[27] J. Dogger, B. Roossien, and F. Nieuwenhout, "Characterization of Liion batteries for intelligent management of distributed grid-connected storage," IEEE Trans. Energy Convers., vol. 26, no. 1, pp. 256-263, Mar. 2011.

[28] D. Janssens, E. Moons, E. Nuyts, and G. Wets. (2013, Dec.) Onderzoek Verplaatsingsgedrag Vlaanderen 3 (2007-2008). [Online]. Available: http://www.mobielvlaanderen.be/ovg/

[29] "Fuel economy labeling of motor vehicles: Revisions to improve calculation of fuel economy estimates," U.S. Environmental Protection Agency, Tech. Rep. EPA420-R-06-017, Dec. 2006.

[30] A. Mathoy, "Definition and implementation of a global EV charging infrastructure," Final report, Brusa Elektronik. [Online]. Available: http://www.park-charge.ch/documents/EV-infrastructure project.pdf

[31] C. Ricaud and P. Vollet, "Connection system on the recharging spot: A key element for electric vehicles," White Paper, Schneider Electric. [Online]. Available: http://www.schneider-electric.com/sites/corporate/ en/support/white-papers/recharging-spot-electric-vehicles.page

[32] S. Luyten, N. Leemput, F. Geth, J. Van Roy, J. Büscher, and J. Driesen, "Standardization of conductive AC charging infrastructure for electric vehicles," in 22nd Int. Conf. \& Exhibition on Electricity Distribution (CIRED), Stockholm, Sweden, Jun. 2013, pp. 1-4.

[33] T. Lyon, M. Michelin, A. Jongejan, and T. Leahy, "Is "smart charging" policy for electric vehicles worthwhile?" Energy Policy, vol. 41, pp. 259-268, Feb. 2012.

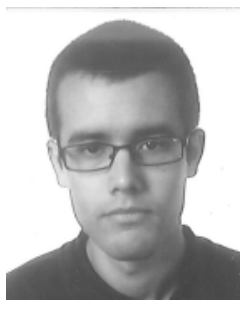

Juan Van Roy (S'09) received the M.Sc. degree in Electrical Engineering with specialization in energy, from the KU Leuven, Belgium, in 2010. Currently, he is working as a research assistant with the division ESAT-Electa towards the Ph.D. degree at the KU Leuven. He is funded through a VITO doctoral scholarship and is enrolled in the KIC InnoEnergy $\mathrm{PhD}$ School

His research interests include integrating and controlling the electric vehicle charging and their interaction with thermal energy flows in buildings.

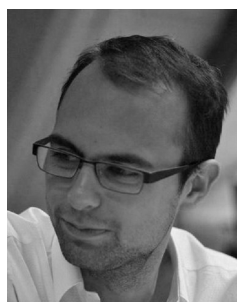

Niels Leemput (S'11) received the M.Sc. degree in Electrical Engineering, with specialization in energy, from the KU Leuven, Belgium, in 2010. Currently, he is working as a research assistant with the division ESAT-Electa towards the Ph.D. degree at the KU Leuven. $\mathrm{He}$ is funded by IWT-Vlaanderen and is enrolled in the KIC InnoEnergy PhD School.

His research interests include the grid integration of charging infrastructure for electric vehicles and power electronics for grid-coupling of electrical vehicles.

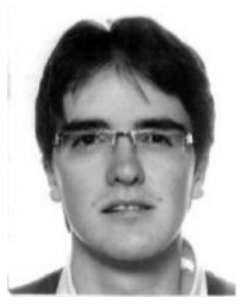

Frederik Geth (S'10) received the M.Sc. degree in Electrical Engineering from the KU Leuven, Belgium, in 2009. Currently, he is working as a research assistant with the division ESAT-Electa towards the $\mathrm{Ph} . \mathrm{D}$. degree at the KU Leuven. He is enrolled in the KIC InnoEnergy PhD School.

His research interests include optimal storage integration in distribution grids, batteries for (hybrid) electrical vehicles and controlling the impact of the charging currents of (hybrid) electrical vehicles on the grid.

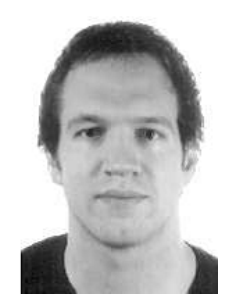

Jeroen Büscher (M'11) received his M.Sc and $\mathrm{Ph} . \mathrm{D}$. degree in Physics at the University of Ghent in 2005 and at the KU Leuven in 2010, respectively. In 2011 he joined the ESAT-Electa division of the KU Leuven as a postdoctoral researcher.

His interests include the smart grid integration of charging infrastructure for electric vehicles and the modeling of electrical energy systems.

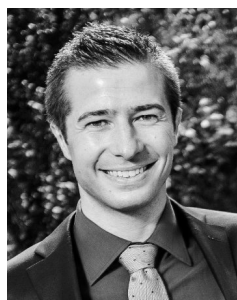

Robbe Salenbien received his M.Sc and Ph.D. degree in Physics at the KU Leuven in 2007 and 2012 respectively. Currently, he is working as a researcher in energy technology at the Flemish Institute for Technological Research (VITO).

His interests include renewable energy technologies, thermal networks, smart energy districts and intelligent energy management

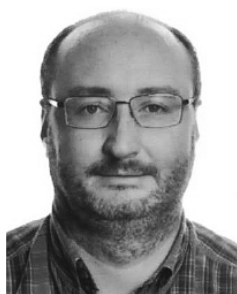

Johan Driesen (S'93 - M'97 - SM'12) received the M.Sc. and Ph.D. degrees in Electrical Engineering from the KU Leuven, Leuven, Belgium, in 1996 and 2000 , respectively. Currently, he is a Professor with the KU Leuven and teaches power electronics and electric drives.

In 2000, he was with the Imperial College of Science, Technology and Medicine, London, U.K. In 2002, he was with the University of California, Berkeley.

Currently, he conducts research on distributed generation, power electronics, and its applications. 